\title{
Optimization for Circulating Cooling Water Distribution of Indirect Dry Cooling System in a Thermal Power Plant under Crosswind Condition with Evolution Strategies Algorithm
}

\author{
Zhao Li, Huimin Wei *, Tao Wu and Xiaoze Du (1D \\ Key Laboratory of Power Station Energy Transfer Conversion and System, School of Energy, Power and \\ Mechanical Engineering, North China Electric Power University, Ministry of Education, Beijing 102206, China; \\ zhaoli@ncepu.edu.cn (Z.L.); wutao_921006@163.com (T.W.); duxz@ncepu.edu.cn (X.D.) \\ * Correspondence: weihm@ncepu.edu.cn
}

check for

updates

Citation: Li, Z.; Wei, H.; Wu, T.; $\mathrm{Du}, \mathrm{X}$. Optimization for Circulating Cooling Water Distribution of Indirect Dry Cooling System in a Thermal Power Plant under Crosswind Condition with Evolution Strategies Algorithm. Energies 2021, 14, 1167. https://doi.org/10.3390/ en14041167

Academic Editor: Bruno Facchini

Received: 15 December 2020

Accepted: 16 February 2021

Published: 22 February 2021

Publisher's Note: MDPI stays neutral with regard to jurisdictional claims in published maps and institutional affiliations.

Copyright: (c) 2021 by the authors. Licensee MDPI, Basel, Switzerland. This article is an open access article distributed under the terms and conditions of the Creative Commons Attribution (CC BY) license (https:/ / creativecommons.org/licenses/by/ $4.0 /)$.

\begin{abstract}
Crosswind has an adverse impact on the performance of an indirect dry cooling system. In order to mitigate the adverse influence, this study redistributed the circulating cooling water among air-cooled heat exchanger sectors so that the performance of the indirect dry cooling system could be improved. An evolution strategies algorithm combined with numerical effectiveness-based heat exchanger model was established to minimize the operation costs of the whole system. Based on a $660 \mathrm{MW}$ practical power plant, optimal circulating cooling water operation strategies under varied crosswind speeds and ambient temperatures were calculated to show its application. According to the calculated results, the performance of the indirect dry cooling system could be enhanced by optimizing circulating cooling water distribution under any crosswind speed, especially under high ambient wind speeds. There is a slight promotion of the coal savings with a rise in ambient temperature: improvements of about $5 \%$. The standard coal consumption rate could save as much as $2.50 \mathrm{~g} / \mathrm{kWh}$ under crosswind speed of $10 \mathrm{~m} \mathrm{~s}^{-1}$ and ambient temperature of $32{ }^{\circ} \mathrm{C}$, compared to the $0.1 \mathrm{~g} / \mathrm{kWh}$ under crosswind speed of $2 \mathrm{~m} \mathrm{~s}^{-1}$ and ambient temperature of $32^{\circ} \mathrm{C}$.
\end{abstract}

Keywords: indirect dry cooling system; crosswind; operation optimization; evolution strategies

\section{Introduction}

In arid regions, many thermal power plants adapt the indirect dry cooling system to cool the exhausted steam of a steam turbine, because this kind of cooling system has outstanding water saving ability [1]. In an indirect dry cooling system, the natural draft dry cooling tower (NDDCT) is the most important facility. With the air-cooled heat exchanger bundles arranged vertically around the circumference of the tower or horizontally inside the tower, cooling air actuated by buoyancy force flows through the air-cooled heat exchanger bundles, taking away the heat rejected by circulating cooling water inside the bundles [2]. Due to the mechanism of NDDCT, the performance of the indirect dry cooling system is very sensitive to ambient conditions, especially the crosswind.

The adverse effect of crosswind on the performance of NDDCT has been widely studied by previous researchers. According to Du Preez and Kröger's [3-5] full scale measurements and numerical simulation, the negative action of crosswinds on a cooling tower with a horizontal heat exchanger arrangement was mainly due to the flow losses at the tower inlet and the distortion in the velocity profile through the heat exchangers, while the poor performance of a cooling tower with vertically arranged heat exchangers was because of the distorted air flow distribution through the heat exchangers. Al-Waked and Behnia's [6] numerical results showed that crosswind could degrade the thermal effectiveness of NDDCT by more than $30 \%$ at crosswind velocities higher than $10 \mathrm{~m} \mathrm{~s}^{-1}$.

By means of numerical simulation, $\mathrm{Su}$ et al. [7] found out that under the situation with cross wind, the fluid flow around the tower was similar to the flow around a circular 
cylinder. The tangential velocity was very large, and the pressure was low at the side part, almost no air flowed through the heat exchangers. This conclusion was validated by Yang et al.'s research [8,9]. Further, Zhao et al.'s [10,11] research revealed that at tower lateral sections, the crosswind induced large air inflow deviation degree at delta entries and caused a low velocity air recirculation zone, leading to the deterioration of the heat exchangers' performance.

In order to relieve the adverse impact of crosswind, the windbreak walls or deflectors method is proposed. Al-Waked and Behnia [12] pointed out that the introduction of windbreak walls could improve the thermal performance of NDDCT, and this positive effect could be enhanced by optimizing the location of windbreak walls. By experimental and numerical approaches, Zhai and Fu [13] found out that windbreak walls placed at the lateral sides of the cooling towers was a straightforward and effective method, which could recover about $50 \%$ of the reduced cooling capacity. Moreover, many layout methods and structures of windbreak walls or deflectors were proposed and studied, such as the interior and exterior windbreaker configurations [14], the internal flat and combination of internal flat-external rounded windbreakers [15], the tri-blade-like windbreak walls [16-18], and so on [19-21]. All these windbreak walls with different arrangement and structures were proved to be very effective in improving the performance of NDDCT under crosswind condition. Further, Zhao et al.'s research [22] revealed that the effect mechanism of air deflectors was that air deflectors could alter the radial inflow air velocity and the air inflow deviation degree. Based on this mechanism, Ma et al. [23] designed an optimal layout of deflectors, in which the setting angles of deflectors were equal to air inflow deviation angles. The numerical results showed that compared to the previous radial deflectors, deflectors with the optimal layout were extremely effective.

Besides the windbreak walls and deflectors methods, Goodarzi pointed out that a new exit configuration for tower stack [24] and alternative tower shell geometry with elliptical cross section [25] could both improve the cooling efficiency of NDDCT under crosswind. Moreover, according to Liao et al. and Kong et al.'s studies [26,27], cooling towers with triangularly or bilaterally arranged air-cooled heat exchanger had better thermo-flow performances at various wind speeds.

However, all these aforementioned methods are all focus on the "air side", while recently an approach on the "water side" was studied by some researchers. The main idea of this approach is to re-distribute the circulating cooling water among air-cooled heat exchangers, so that the performance of NDDCT under crosswind condition could be improved. This approach was firstly proposed by Li et al. [28], their distribution method was that for one heat exchanger, the proportion of water mass flow rate to the total was equal to the proportion of air mass flow rate to the total. This distribution method has been proved to be effective by their calculating results, but this method cannot provide the optimal water distribution under crosswind condition. In order to obtain the optimal circulating cooling water distribution, Wei et al. [29] and Wang et al. [30] used entransy theory to build the optimization model. This model has definite physical meaning, but due to the mechanism of entransy theory, the optimization model is very complex. On the other hand, Goodarzi and Amooie [31] tried to solve this problem in mathematical way, they used genetic algorithm to calculate the optimal water distribution, but their study was only about the cooling tower itself; this caused a lack of practical significance in a way because the cooling tower was just a part of the whole power generating system, the optimal thermo-flow performance of a single unit did not correspond to the optimal operation point of a system [32,33].

To address the above problems, a substitution model based on the numerical effectiveness in this study is established to reduce the computing time. Combined with the $(\mu / \rho, \lambda)$-ES algorithm, with full consideration of the variations of operation costs due to the change of waterside, a global optimization model of the waterside distribution is proposed to minimize the cost function. At the final part, a practical $660 \mathrm{MW}$ supercritical 
thermal power plant with an indirect dry cooling system, the main power generating units in mainland China, is taken as the study object to show the application.

\section{System Description}

The thermal-fluid process of the investigated $660 \mathrm{MW}$ supercritical thermal power plant with indirect dry cooling system is shown in Figure 1. The feed water is converted into superheated steam by the boiler, and then the steam expands in the turbine to output mechanical power which drives the alternator to generate electrical energy. At the same time, some of the steam passing through the turbine is bled at a series of openings to heat the feed water in heaters. The exhausted steam out of the turbine is cooled by the indirect dry cooling system and condensed into water which goes back to the boiler. The main operating parameters of the investigated power plant under design condition are listed in Table 1.

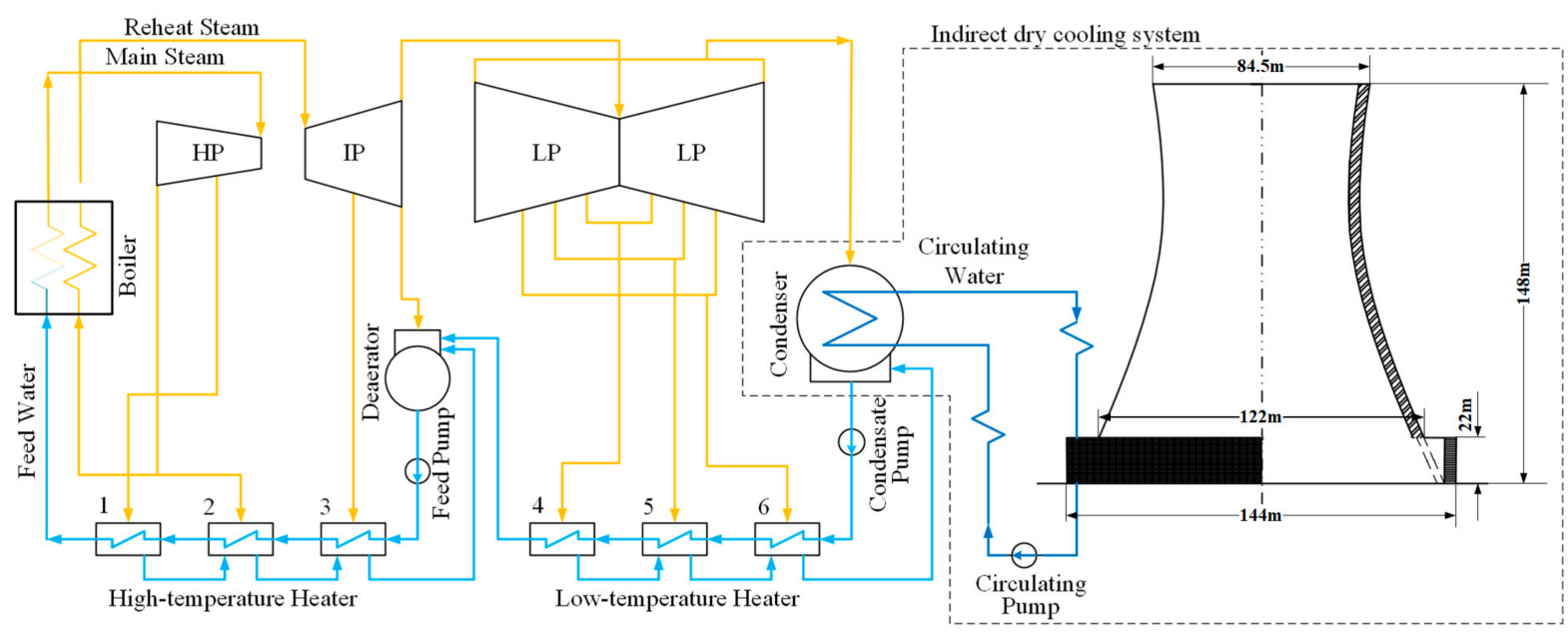

Figure 1. Schematic of the thermal-fluid process of the indirect dry cooling power plant.

Table 1. Designed parameters of the power plant.

\begin{tabular}{cc}
\hline Operation Parameters & Values \\
\hline Main steam mass flow rate & $1,920,800 \mathrm{~kg} \mathrm{~h}^{-1}$ \\
Main steam specific enthalpy & $3398.8 \mathrm{~kJ} \mathrm{~kg}^{-1}$ \\
Main steam pressure & $24.20 \mathrm{MPa}$ \\
Main steam temperature & $566.0^{\circ} \mathrm{C}$ \\
Reheat steam mass flow rate & $1,575,068 \mathrm{~kg} \mathrm{~h}^{-1}$ \\
Reheat steam specific enthalpy & $3595.3 \mathrm{~kJ} \mathrm{~kg}^{-1}$ \\
Reheat steam pressure & $4.176 \mathrm{MPa}$ \\
Reheat steam temperature & $566.0^{\circ} \mathrm{C}$ \\
Exhausted steam mass flow rate & $1,139,878 \mathrm{~kg} \mathrm{~h}^{-1}$ \\
Exhausted steam specific enthalpy & $2419.4 \mathrm{~kJ} \mathrm{~kg}^{-1}$ \\
Back pressure & $13.5 \mathrm{kPa}^{2}$ \\
\hline
\end{tabular}

According to Figure 1, the NDDCT in the indirect dry cooling system has a hyperbolic shell and incorporates vertically arranged air-cooled heat exchangers. Heat exchangers consists of slotted aluminum plate finned tubes, as shown in Figure 2. The dense fins lead airflow passing through the heat exchangers horizontally. 


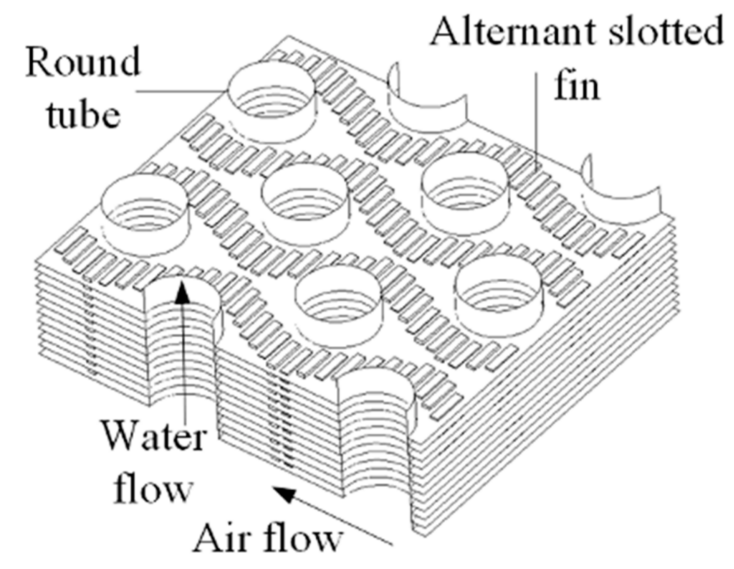

Figure 2. Details of heat exchangers.

These air-cooled heat exchangers are composed of many cooling columns which are connected by support structures, as shown in Figure 3. Considering the axial-symmetrical structure of the tower and the air-cooled heat exchangers, only half of the tower and aircooled heat exchangers is taken into account so that the computing resource and computing time could be saved.

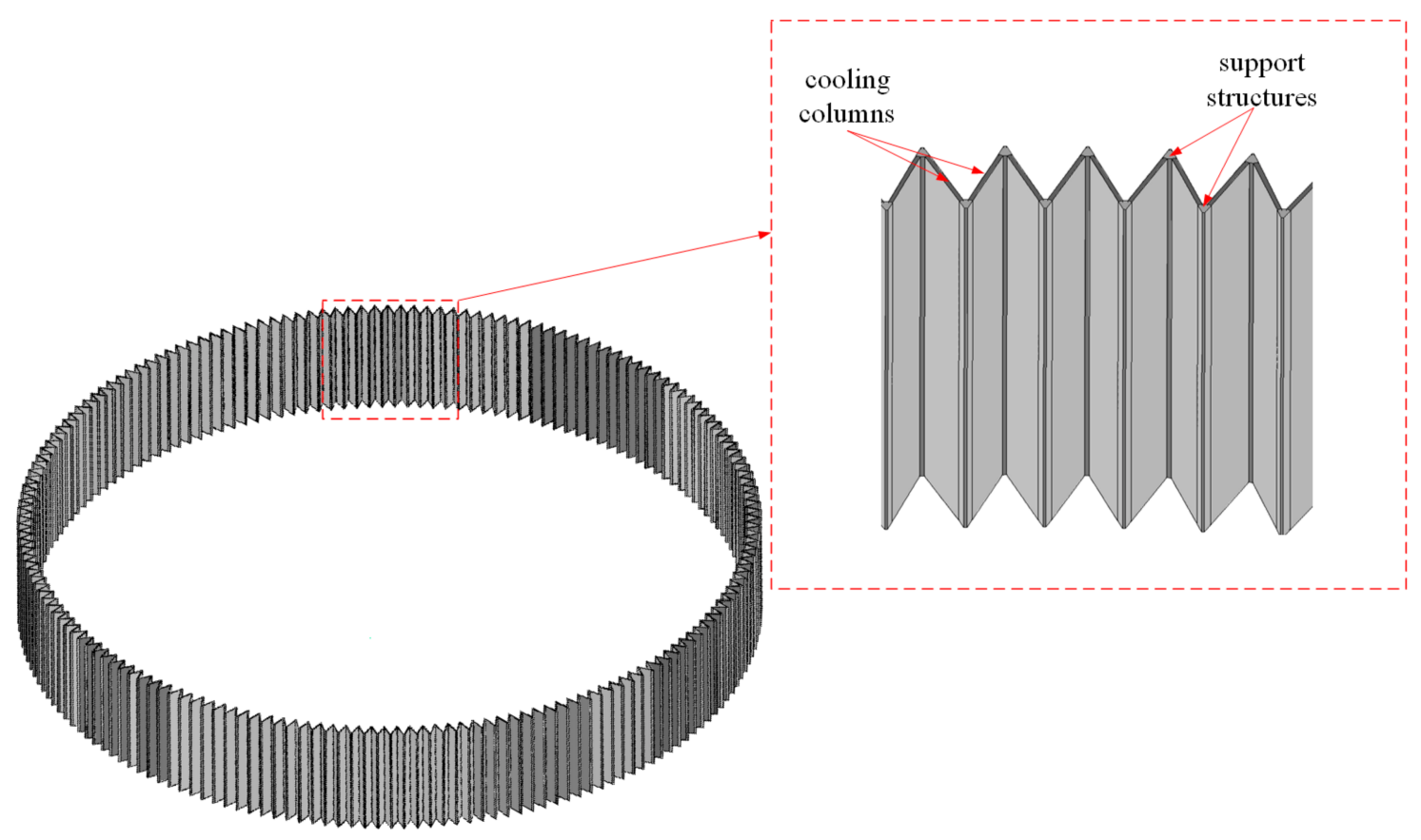

Figure 3. Configuration of the air-cooled heat exchangers.

For easy distribution of the circulating cooling water, the air-cooled heat exchangers are divided into several sectors in practical engineering. In this study, for the investigated half of the air-cooled heat exchangers, there are five sectors, as shown in Figure 4. In Sectors 1, 3 and 5 , there are 36 cooling columns, while in Sectors 2 and 4, there are 34 cooling columns. In one sector, circulating cooling water is evenly distributed among cooling columns. 


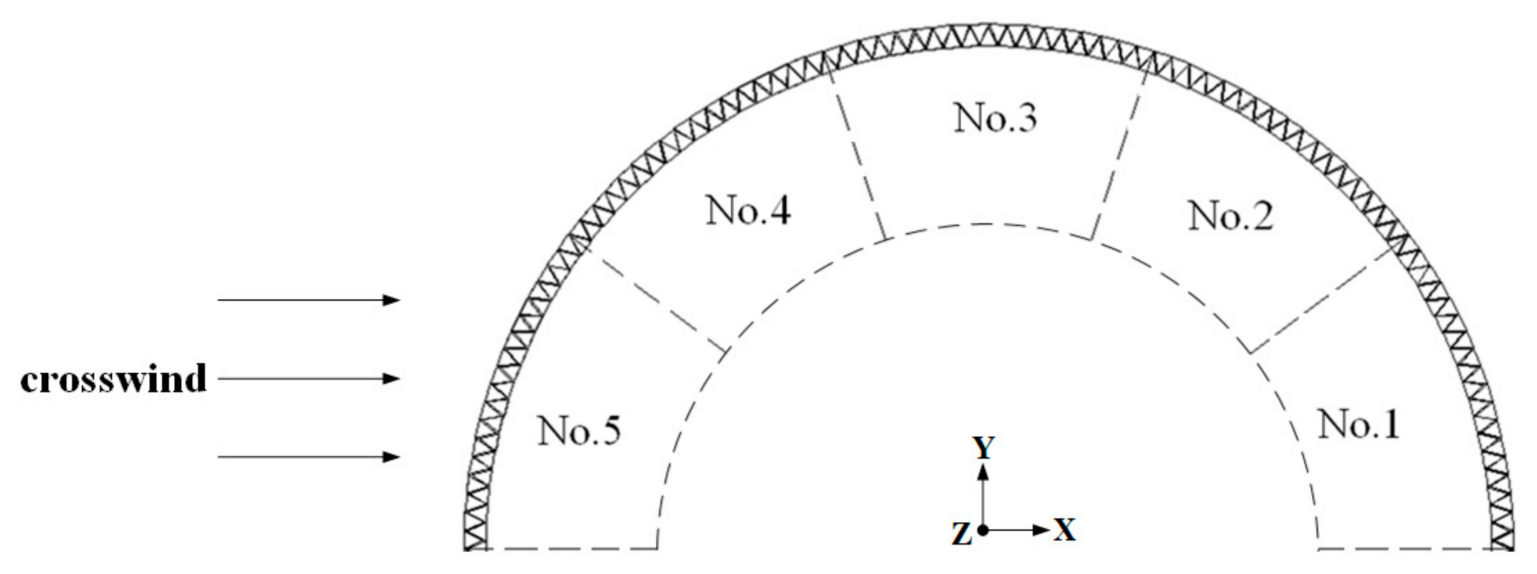

Figure 4. Sector arrangement.

\section{Methodologies}

\subsection{Mathematical Models of Thermal-Fluid Process}

The calculation of the thermal-fluid process described above is a coupled algorithm that includes the thermodynamic model of a turbine and regenerative heating system and the numerical model of NDDCT.

The thermodynamic model describes the steam characteristics in turbine, condenser and regenerative heating system under off-design conditions. For the turbine, Flugel formula [32] is mainly used,

$$
\frac{D}{D_{0}}=\sqrt{\frac{P_{1}^{2}-P_{2}^{2}}{P_{10}^{2}-P_{20}^{2}}} \sqrt{\frac{T_{10}}{T_{1}}}
$$

where $D$ is steam mass flow rate, $P$ and $T$ represent the pressure and temperature of steam, respectively. The subscript 1 and 2 mean before and after stage group, and the subscript 0 represents the previous condition.

For the regenerative heating system, Equation (2), which is derived from the heat balance equations of heaters, is adopted [29],

$$
D_{e s, j}=\frac{D_{f w, i} \tau_{j}-D_{d} \gamma_{j}}{q_{j}}
$$

where $D_{e s}, D_{f w}$ and $D_{d}$ are the mass flow rate of extraction steam, feed water and drainage water, respectively. $\tau$ is the specific enthalpy rise of feed water, $\gamma$ and $q$ are heat output of drainage water and extraction steam. The subscript $j$ represents the $j$ th extraction.

On the other hand, a 3D numerical model of NDDCT is used to calculate the performance of NDDCT under various ambient conditions. In the numerical model, the governing equations with boundary conditions are discretized with the second-order upwind differencing method. Pressure and velocity solutions are coupled by the SIMPLE algorithm. The computational domain and boundary conditions are shown in Figure 5. With a width of $1500 \mathrm{~m}$ and height of $800 \mathrm{~m}$ of the computational domain, a fully developed flow can be ensured. The detailed mesh can be seen in our previous study [34,35].

Then, the steam characteristics under certain ambient conditions can be obtained, hence, the output power of the plant, $P_{e}$, is calculated by,

$$
P_{e}=\frac{D_{c} \Delta h_{c}+\sum D_{e s, j} \Delta h_{e s, j}}{\eta_{m} \eta_{g}}
$$


where $\Delta h_{c}$ and $\Delta h_{e s}$ are the actual specific enthalpy drop of exhausted steam and extraction steam, $\eta_{m}$ and $\eta_{g}$ which are regarded as constant and represent the mechanical efficiency and the effectiveness of generator, respectively.

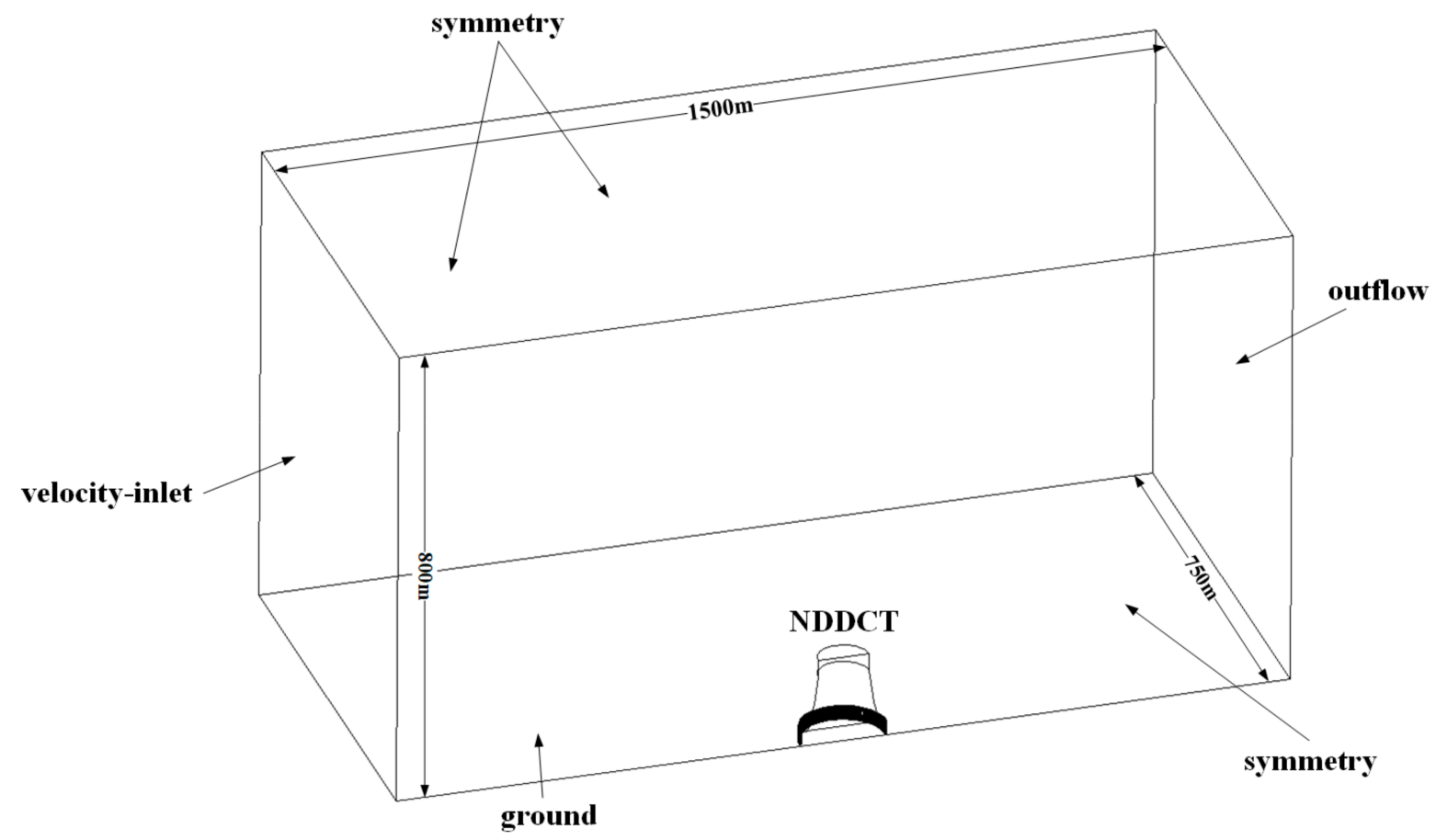

Figure 5. Computational domain and boundary conditions of natural draft dry cooling tower (NDDCT).

In order to obtain the standard coal consumption rate, $P_{w}$, which means the power required to pump circulating cooling water through air-cooled heat exchangers, is calculated as,

$$
P_{w}=\sum P_{w, c l}
$$

where $P_{w, c l}$ is the power required to pump circulating cooling water through one cooling column and can be calculated by $[35,36]$,

$$
P_{w, c l}=\pi d^{2} \Delta p_{w} G_{w} L n_{t b} n_{b} / 4 \rho_{w}
$$

where $\Delta p_{w}=\frac{f G_{w}^{2}}{2 \rho_{w} d}$ and $G_{w}=\frac{4 D_{w, c l} n_{w p}}{\pi d^{2} n_{t b} n_{b}}$.

Further, the standard coal consumption rate, $b_{0}$ can be calculated by,

$$
b_{0}=\frac{D_{m s}\left(h_{m s, 2}-h_{m s, 1}\right)+D_{r e h}\left(h_{r e h, 2}-h_{r e h, 1}\right)}{\eta_{b} \eta_{p} Q_{s c}\left(P_{e}-P_{w}\right)} \times 10^{6}
$$

where $D_{m s}$ and $D_{\text {reh }}$ are the mass flow rate of main steam and reheat steam, $h_{m s}$ and $h_{r e h}$ are the specific enthalpy of main steam and reheat steam, $Q_{s c}$ is calorific value of standard coal, $\eta_{b}$ and $\eta_{p}$, which are regarded as constant, represent the effectiveness of boiler and pipeline, respectively.

\subsection{Evolution Strategies Based Optimization Model}

An evolution strategy in an optimization technique based on ideas of evolution. It is a population-based algorithm that has three major operators: recombination, mutation and selection of parents [37]. In practical use, the operators are applied in a loop. An iteration of the loop is called a generation. The sequence of generations is continued until a termination criterion is met. 
The goal of an evolution strategy is to minimize (or maximize) an objective function $F$ with respect to a set of decision variables or control parameters $x=\left(x_{1}, x_{2}, \ldots\right)$ [38]

$$
F(x) \rightarrow o p t
$$

Evolution strategies operate on populations $\mathrm{G}$ of individuals $\alpha$. An individual with index $k$ comprises not only the specific objective parameter set $x_{k}$ and its objective function value $F_{k}=F\left(x_{k}\right)$, but also a set of endogenous strategy parameters $\sigma_{k}$ which helps guide individuals towards the optimum [39],

$$
\boldsymbol{\alpha}_{k}=\left(\boldsymbol{x}_{k}, \sigma_{k}, F\left(x_{k}\right)\right)
$$

In this study, the classical $(\mu / \rho, \lambda)$-ES algorithm is adopted. The procedure of the algorithm is illustrated by pseudo-code in Algorithm 1 [40]. At generation $g=0$, the parent population $\mathrm{G}_{\mathrm{par}}^{0}$ is initialized. After initialization, the repeat-until-loop is entered. From the parental population $\mathrm{G}_{\text {par, }}^{\mathrm{g}}$ at generation $g$ a new offspring population $\mathrm{G}_{\text {off }}^{\mathrm{g}}$ is produced by running $\lambda$ times through the lines $6-10$. Each cycle generates one offspring: first, the recombination of the endogenous strategy parameters takes place in line 6 and for the object parameters in line 7 . Then, the mutation of the strategy parameters is done in line 8 and those of the object parameters in line 9. Finally, the objective function value is calculated in line 10. After having a complete offspring population $\mathrm{G}_{\mathrm{off}}^{\mathrm{g}}$, the best $\mu$ individuals in it are selected to form a new parent population $G_{\text {par }}^{\mathrm{g}+1}$, and then, the algorithm goes to the next generation step until the termination condition is satisfied.

Detail description of Algorithm 1 is as follows.

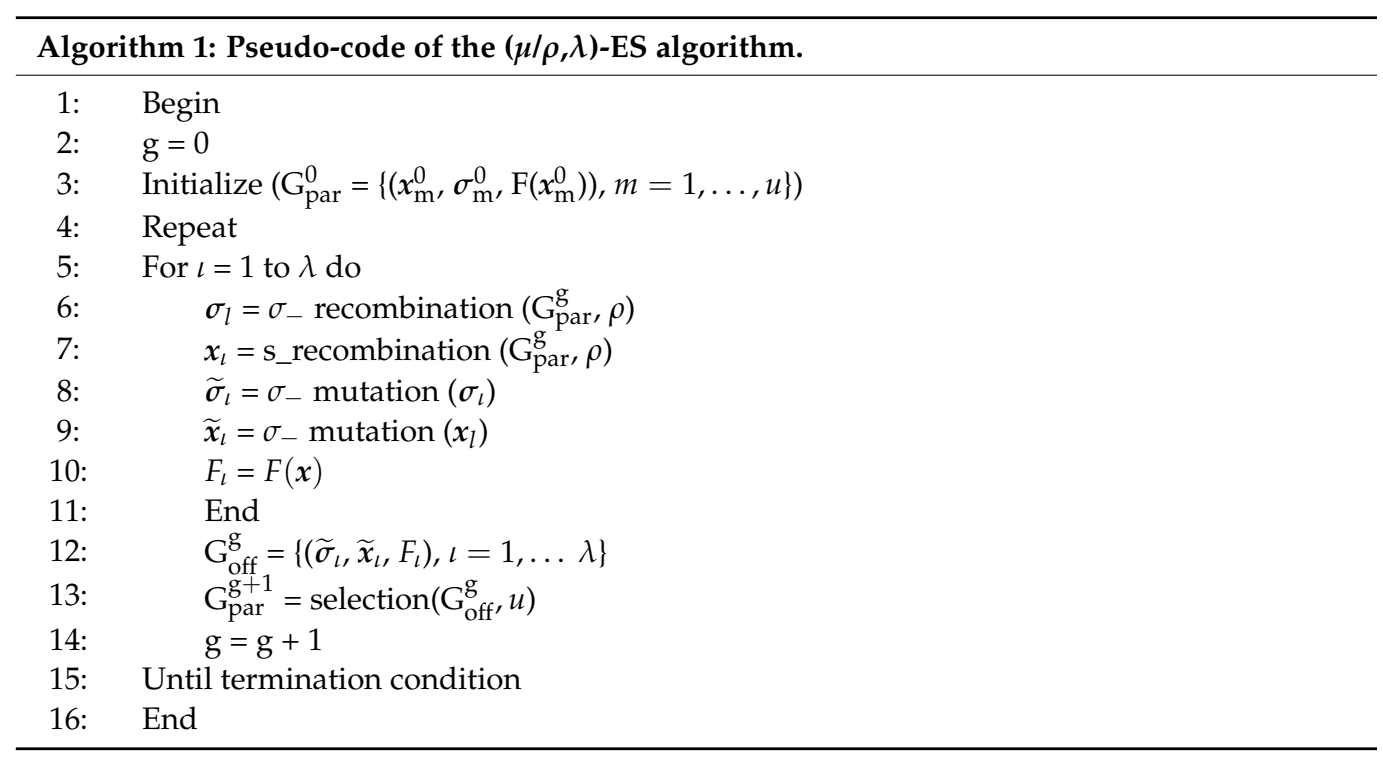

\subsubsection{Recombination}

The intermediate recombination is adopted for both the endogenous strategy parameters and the objective parameters. The formula is [40],

$$
\begin{gathered}
\sigma_{l}=\frac{1}{\rho} \sum_{i=1}^{\rho} \sigma_{i} \\
x_{l}=\frac{1}{\rho} \sum_{i=1}^{\rho} x_{i}
\end{gathered}
$$

where $\sigma_{i}$ and $x_{i}$ are chosen randomly from the parental population, $\rho$ is a predetermined fixed number which is set as 2 in this study. 


\subsubsection{Mutation}

For the endogenous strategy parameters $\sigma=\left(\sigma_{1}, \ldots, \sigma_{N}\right)$, the multiplicative mutation technique is used.

$$
\widetilde{\sigma}=\exp \left(\tau_{0} N_{0}(0,1)\right) \bullet\left[\sigma_{1} \exp \left(\tau N_{1}(0,1)\right), \ldots, \sigma_{N} \exp \left(\tau N_{N}(0,1)\right)\right]
$$

The idea here is that each component of $\sigma$ is mutated independently and finally the whole vector is scaled by the random factor $\exp \left(\tau_{0} N_{0}(0,1)\right)$. In Equation (11), the $N_{i}(0,1)$ are independent random samples from the standard normal distribution, $\tau_{0}$ and $\tau$ are learning parameters which can be calculated as follows according to Schwefel [41].

$$
\tau_{0}=\frac{1}{\sqrt{2 N}} \text { and } \tau=\frac{1}{\sqrt{2 \sqrt{N}}}
$$

Further, for the objective parameters $x=\left(x_{1}, \ldots, x_{N}\right)$, the mutation process can be performed by,

$$
\widetilde{\boldsymbol{x}}=\boldsymbol{x}+\widetilde{\boldsymbol{\sigma}}\left(N_{1}(0,1), \ldots, N_{N}(0,1)\right)
$$

In this study, $N$ is set as 4 and $x_{1}$ to $x_{4}$, respectively, refer to the mass flow rate of circulating cooling water in Sector 1 to Sector 4 . The mass flow rate of circulating cooling water in Sector 5 is obtained by subtracting the mass flow rate in the other sectors from half of the total mass flow rate (because only half of the NDDCT is investigated), so that the total mass flow rate of circulating cooling water can remain unchanged as $19,419 \mathrm{~kg} \mathrm{~s}^{-1}$.

\subsubsection{Objective Function}

For the problem investigated in this study, the objective function is used to calculate the standard coal consumption rates under different circulating cooling water distributions. This could be done by the calculating model described in Section 3.1, but since in this calculating model the NDDCT is modeled by a numerical method, it is very complex and time-consuming to use the calculating model in the evolution strategies algorithm. In order to smoothly carry out the $(\mu / \rho, \lambda)$-ES algorithm, an approximate model for the NDDCT is built based on the original numerical model.

In the approximate model, a cooling column is considered as a whole and the $\varepsilon-N T U$ method is utilized to calculate its heat transfer process. For a cooling column, the heat transfer rate $Q_{c l}$ could be calculated by,

$$
Q_{c l}=\varepsilon m_{a, c l} c_{p a}\left(T_{w 1}-T_{a 1}\right)
$$

where $T_{w 1}$ and $T_{a 1}$ are the inlet temperature of water and air, $m_{a, c l}$ is the air mass flow rate of the cooling column which can be obtained by the numerical model, $\varepsilon$ is the effectiveness which is defined as,

$$
\varepsilon=1-\exp \left\{-\frac{1}{C_{r}} N T U^{0.22}\left[1-\exp \left(-C_{r} N T U^{0.78}\right)\right]\right\}
$$

where $C_{r}$ is the ratio of the heat capacity rate of air to that of water, NTU is the number of transfer units with the following form,

$$
N T U=\frac{K A}{m_{a, c l} c_{p a}}
$$

where $K$ and $A$ are the overall heat transfer coefficient and area, respectively [2].

The total heat transfer rate of NDDCT $Q_{\text {tot }}$ can be calculated by summing up all the heart transfer rates of cooling columns.

$$
Q_{t o t}=\sum Q_{c l}
$$


In order to validate the approximate model, both the numerical model and the approximate model are used to calculate the heat transfer rates of a sample of the air-cooled heat exchanger in the investigated NDDCT with different frontal velocity of air. Experimental wind-tunnel tests are chosen as references [42], since airflow generated by a wind tunnel is almost uniform. Comparative results are shown in Figure 6. The average deviation and standard deviation of the numerical model are $3.802 \%$ and $3.98 \%$, respectively, while they are $3.691 \%$ and $4.1 \%$ for the approximate model. Considering the air velocity distribution of a heat exchange column, usually with a maximum of $3.5 \mathrm{~m} / \mathrm{s}$, it could be concluded that both the two models are accurate and reliable.

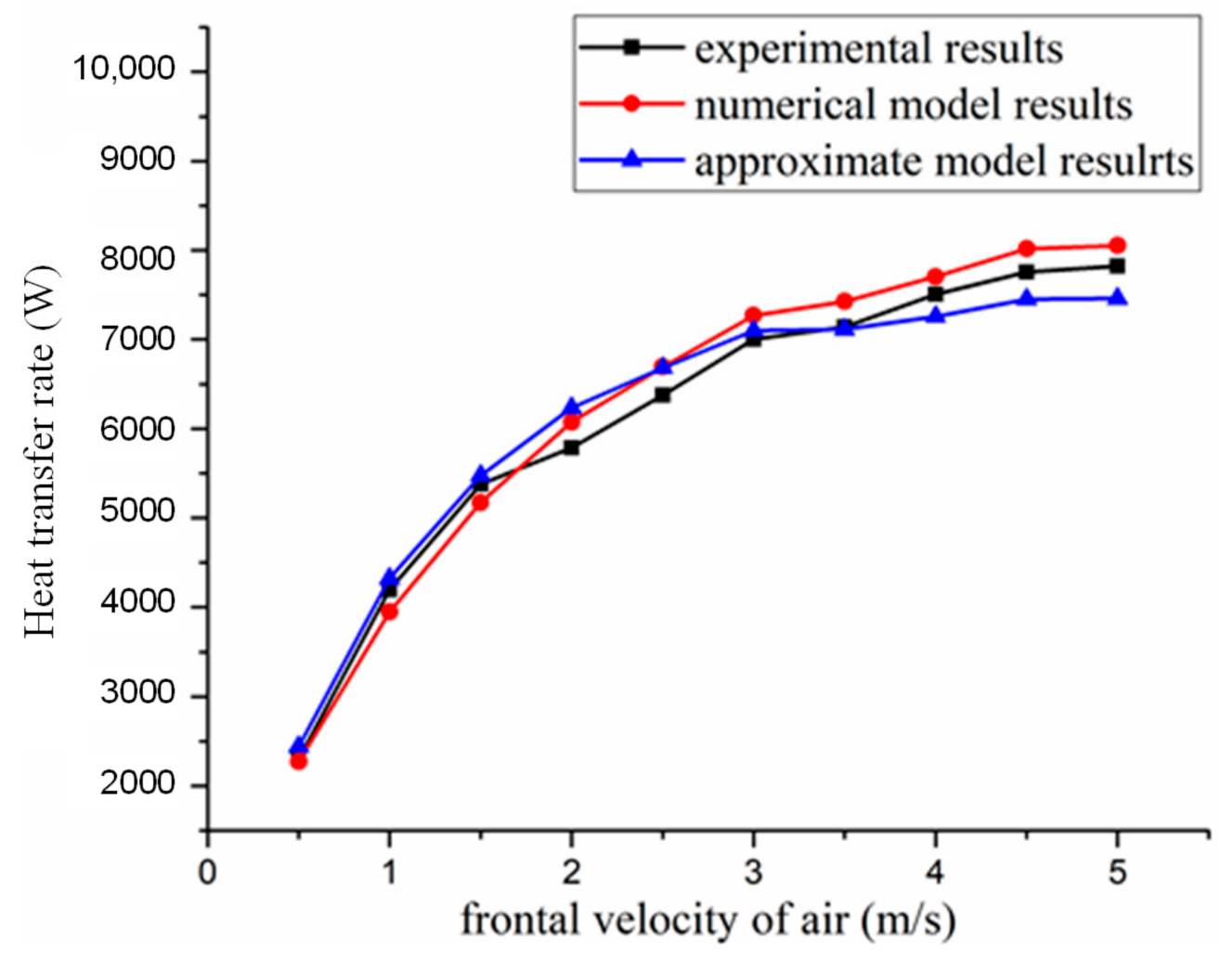

Figure 6. Comparison between experimental and calculating results.

Substitute the approximate model for the numerical model in the calculating model for thermal-fluid process, a substitution model is obtained. Take this substitution model as the objective function, the whole procedure of the $(\mu / \rho, \lambda)$-ES algorithm could be programmed and ran by means of Matlab.

\subsubsection{Selection}

In the selection, $\lambda$ individuals from the $\mathrm{G}_{\text {off }}^{\mathrm{g}}$ compose the selection pool from which the best $\mu$ individuals are selected to form the new parental population. In this study, the best individuals refer to the circulating cooling water distributions which lead to the minimum standard coal consumption rates.

After a couple of trials, the values of $\mu$ and $\lambda$ are finally determined as 60 and 150, respectively.

\subsubsection{Termination Condition}

In this study, the stopping rule-maximum number of generations-is used as the termination condition. After several trials, the maximum number of generations is set as 300 . 


\subsection{Comprehensive Calculation Process andVvalidation}

According to the mechanism of NDDCT, airflow is driven by the pressure difference between the outside and the inside of the tower, hence, the re-distribution of circulating cooling water will cause a slight change of the air mass flow rates of cooling columns [29]. In order to obtain the optimal circulating cooling water distribution, the comprehensive calculation process is iterative, as shown in Figure 7.

\section{Start calculation}

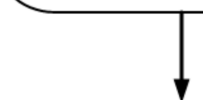

Confirm ambient temperature and crosswind speed.

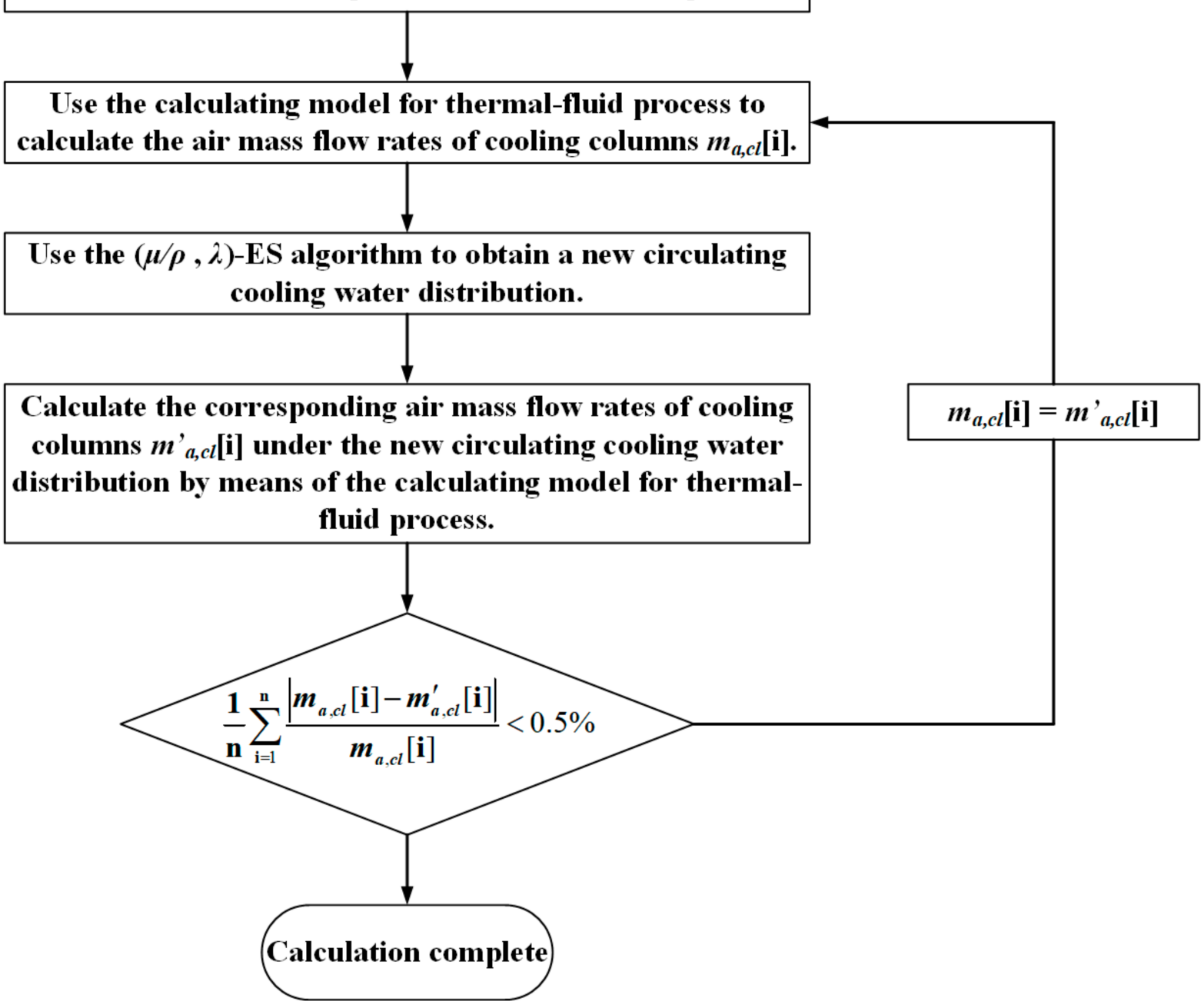

Figure 7. Flow chart of the comprehensive calculation process.

The purpose of the calculation is to obtain the optimal circulating cooling water distribution under certain ambient temperatures and crosswind speeds, thus, at the beginning, the values of the temperature and speed is confirmed. By means of the calculating model for thermal-fluid process, the air mass flow rates of cooling columns $m_{a, c l}[\mathrm{i}]$ can be calculated. Then, utilizing the $(\mu / \rho, \lambda)$-ES algorithm, a new circulating cooling water distribution is obtained. With this new circulating cooling water distribution, the corresponding air mass flow rates of cooling columns $m \prime_{a, c l}[\mathrm{i}]$ can be calculated by the calculating model for the thermal-fluid process. If the average relative error between $m_{a, c l}[\mathrm{i}]$ and $m^{\prime}{ }_{a, c l}[\mathrm{i}]$ is less 
than $0.5 \%$, it is considered that the change in air mass flow rate is negligible, and the new circulating cooling water distribution calculated by the $(\mu / \rho, \lambda)$-ES algorithm is optimum.

Figure 8 shows the optimal circulating cooling water distribution calculated by the aforementioned method and the method in Wei et al.'s research [29]. Obviously, the water distribution calculated by the method in this study and that calculated by the method in Wei et al.'s study [29] are almost the same. The average deviation and standard deviation of the optimal distribution are $1.04 \%$ and $1.38 \%$ under $40{ }^{\circ} \mathrm{C}$ of ambient temperature and $4 \mathrm{~m} \mathrm{~s}^{-1}$ of crosswind speed, while they are $3.691 \%$ and $4.1 \%$ for the approximate model under $40{ }^{\circ} \mathrm{C}$ of ambient temperature, $4 \mathrm{~m} \mathrm{~s}^{-1}$ of crosswind speed and $30{ }^{\circ} \mathrm{C}$ of ambient temperature, $8 \mathrm{~m} \mathrm{~s}^{-1}$ of crosswind speed. It could be concluded that the calculating method for the optimal circulating cooling water distribution proposed in this study is credible.
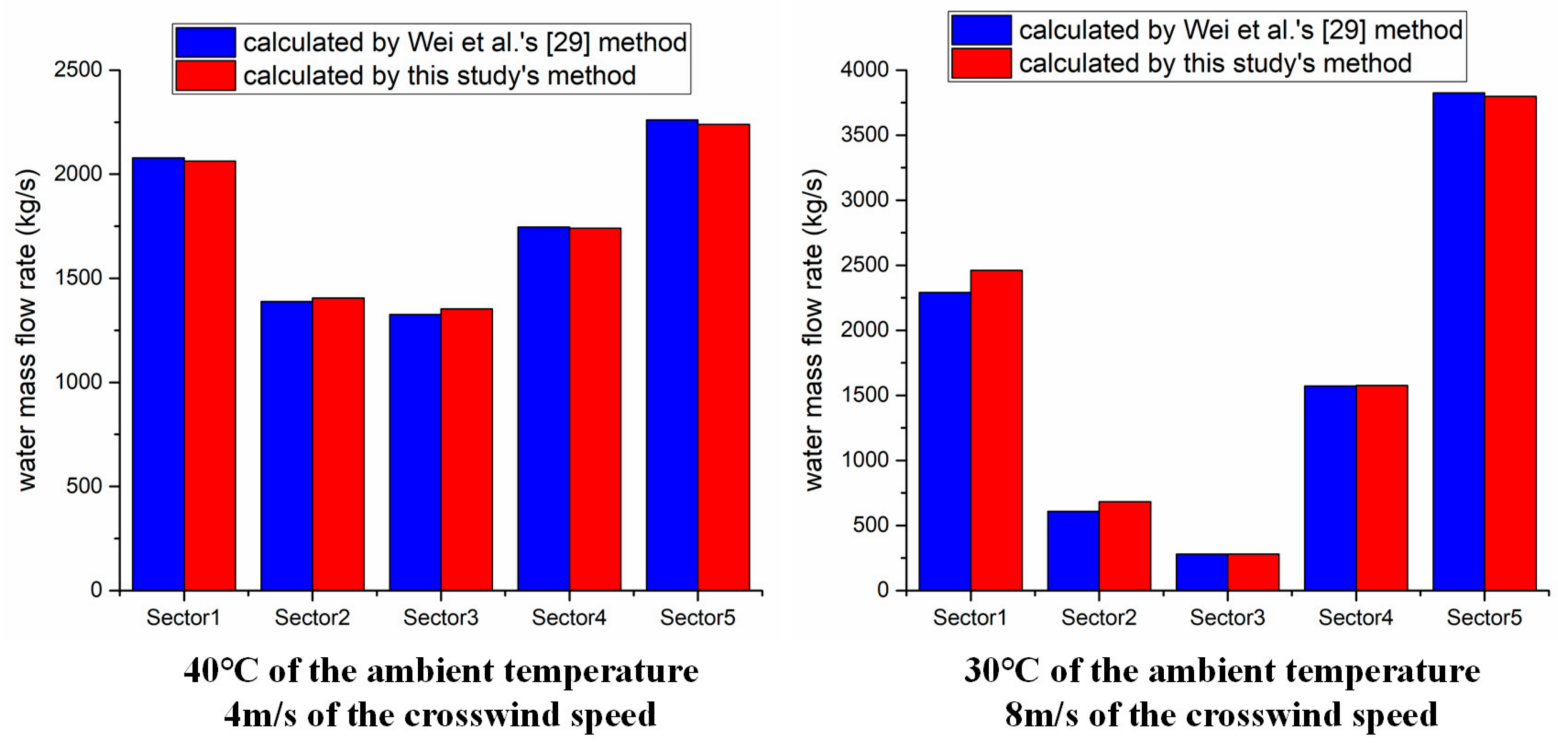

Figure 8. Comparison of the optimal circulating cooling water distribution.

\section{Results and Discussion}

By means of the calculating method introduced in Section 2, the optimal circulating cooling water distributions under different ambient conditions are obtained, the results are shown in Figure 9. Colored areas represent the ratio of mass flow rate pumped into each sector and the total mass flow rate. It could be seen that the windward sector, Sector 5, has the most circulating cooling water and the leeward sector, Sector 1, takes second place; the lateral sector, Sector 3, always has the lowest distribution of circulating cooling water. That is consistent with the airside mass flow rate distribution. The difference in water mass flow rate among sectors becomes bigger with the increase in crosswind speed. However, on the other hand, ambient temperature almost has no effect on the circulating cooling water distribution.

Ambient temperature of $24{ }^{\circ} \mathrm{C}$ with $6 \mathrm{~m} \mathrm{~s}^{-1}$ of crosswind speed as an example, is shown in Figure 10. Ambient wind leads to low-pressure zone in the front of lateral sector, and high-pressure zone in front of the inlet and outside. Then, the optimal waterside distribution tends to pump more water into Sector 1 and Sector 5 to maximize the heat transfer rate. It can also be seen that no matter whether the circulating cooling water is in the uniform distribution or in the optimal distribution, there basically is no difference in the pressure fields and air streamlines at the height of $10 \mathrm{~m}$ as well as the air temperature fields of cooling columns. This indicates that the re-distribution of circulating cooling water has little impact on the air-side thermal-fluid performance. 


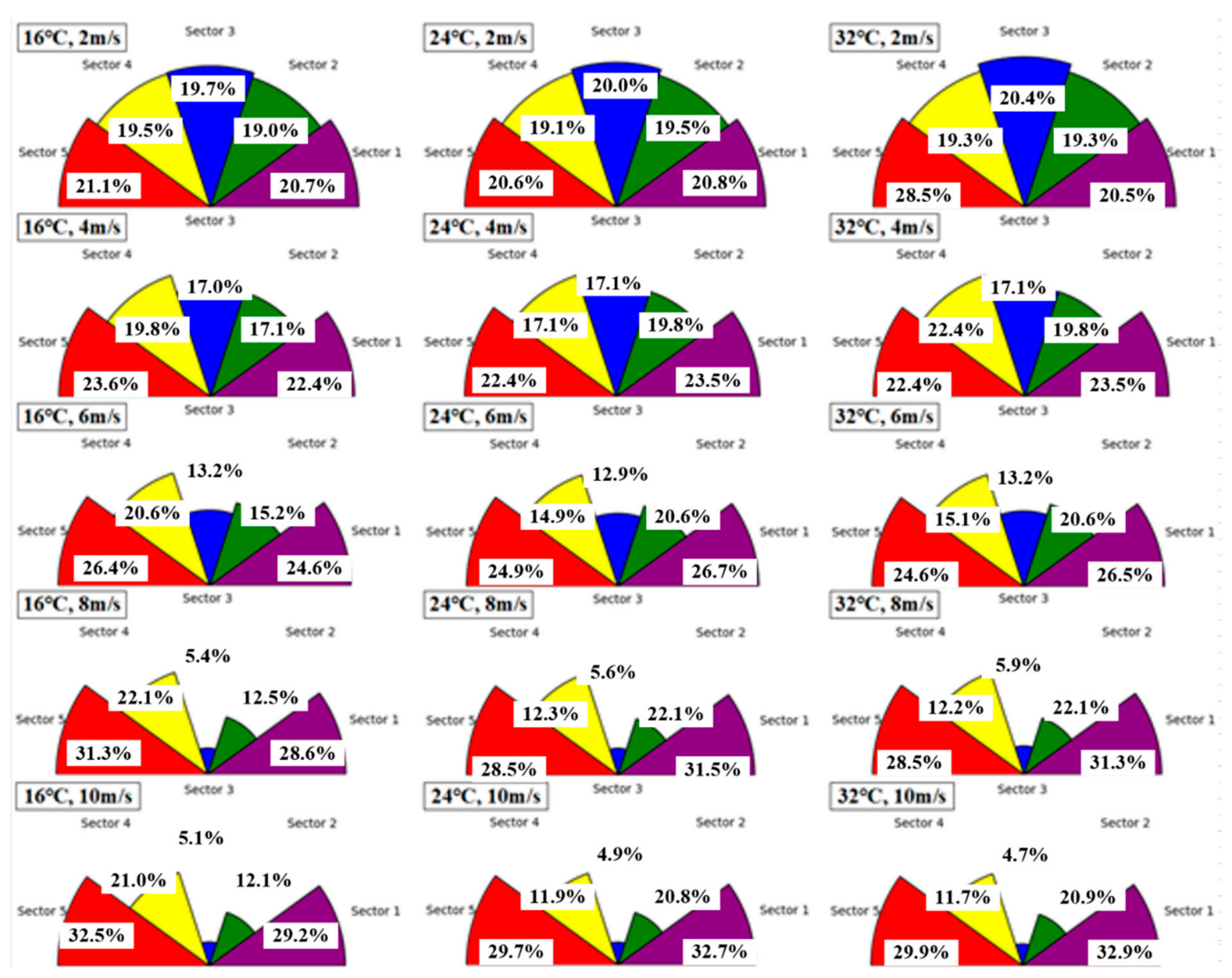

Figure 9. The optimal circulating cooling water distributions under different ambient conditions.

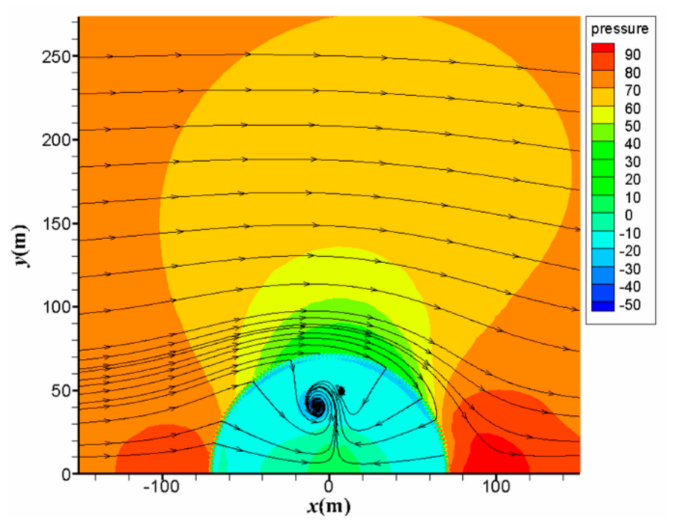

Uniform circulating cooling water distribution

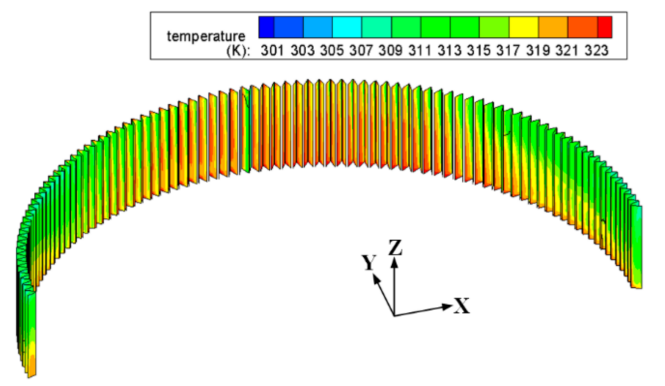

Uniform circulating cooling water distribution

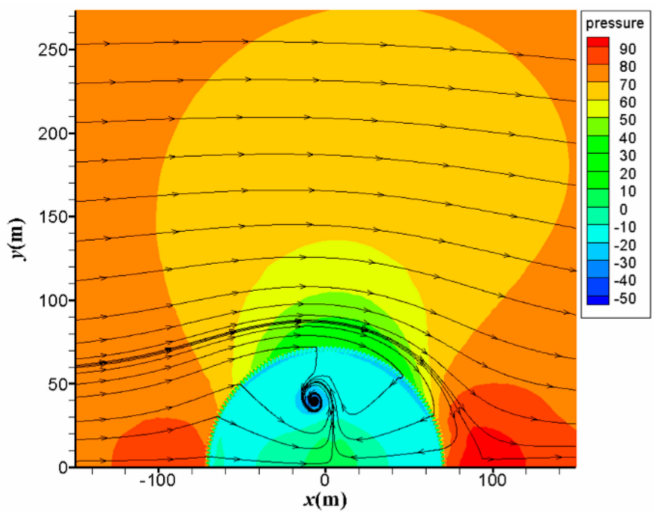

Optimal circulating cooling water distribution

(a)

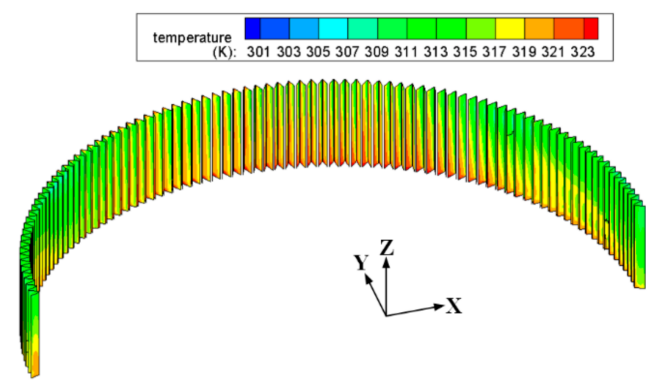

Optimal circulating cooling water distribution

(b)

Figure 10. Variable fields under ambient temperature $24{ }^{\circ} \mathrm{C}$ and crosswind speed $6 \mathrm{~m} \mathrm{~s}^{-1}$ : (a) pressure fields and air streamlines at the height of $10 \mathrm{~m}$ and (b) air temperature fields of cooling columns. 
On the other hand, for the water side, it could be seen from Figure 11 that compared to uniform circulating cooling water distribution, when circulating cooling water is distributed optimally, the outlet water temperature of wind ward sector, Sector 5 is not the lowest because more circulating cooling water is allocated to Sector 5. Similarly, the lateral sector, Sector 3 does not have the highest outlet water temperature because less circulating cooling water is allocated to Sector 3. In general, under optimal circulating cooling water distribution, outlet water temperatures of different sectors tend to be similar. Actually, the variances of outlet water temperatures under optimal distribution and uniform distribution are, respectively, 5.462 and 7.595, corresponding to standard deviations of 2.62 and 3.08. It could be concluded that the optimal distribution for circulating cooling water could improve the homogeneity of outlet water temperatures among sectors.

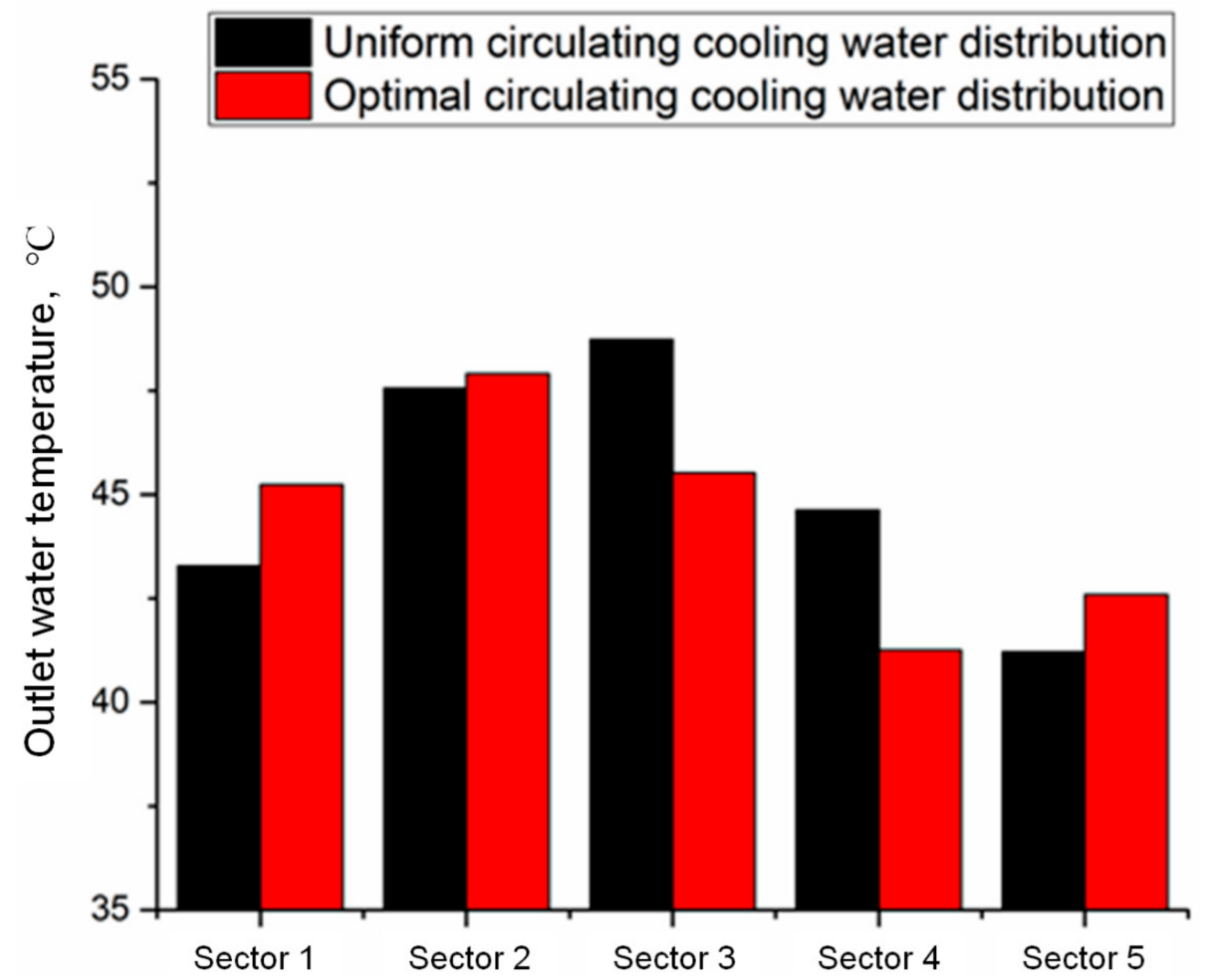

Figure 11. Outlet water temperatures of different sectors under ambient temperature $24{ }^{\circ} \mathrm{C}$ and crosswind speed $6 \mathrm{~m} \mathrm{~s}^{-1}$.

In Table 2, the optimal distributions of circulating cooling water and the corresponding reduced standard coal consumption rates under different ambient conditions are listed. According to the residual error settings in Figure 7, the relative heat transfer rate error of $0.5 \%$ is in correspondence with coal consumption rate of $0.02 \mathrm{~g} / \mathrm{kWh}$, within the error settings. It could be seen that the reduced standard coal consumption rate increases significantly with the increase in crosswind speed. Besides, under low crosswind speed, ambient temperature almost has no effect, but under high crosswind speed, for each kilowatt-hour, more standard coal is saved when ambient temperature becomes higher. The standard coal consumption rate could be reduced by as much as $2.50 \mathrm{~g} / \mathrm{kWh}$ under crosswind speed of $10 \mathrm{~m} \mathrm{~s}^{-1}$ and ambient temperature of $32{ }^{\circ} \mathrm{C}$. 
Table 2. Optimal circulating cooling water distributions and saved standard coal consumption rates.

\begin{tabular}{|c|c|c|c|c|c|c|}
\hline \multicolumn{7}{|c|}{ Ambient Temperature, $16{ }^{\circ} \mathrm{C}$} \\
\hline \multirow{2}{*}{ Crosswind Speed } & \multicolumn{5}{|c|}{ Optimal Circulating Cooling Water Mass Flow Rate (kg/s) } & \multirow{2}{*}{$\begin{array}{l}\text { Reduced Standard Coal } \\
\text { Consumption Rate (g/kWh) }\end{array}$} \\
\hline & Sector 1 & Sector 2 & Sector 3 & Sector 4 & Sector 5 & \\
\hline $2 \mathrm{~m} \mathrm{~s}^{-1}$ & 2008.47 & 1842.92 & 1911.89 & 1897.12 & 2049.01 & 0.10 \\
\hline $4 \mathrm{~m} \mathrm{~s}^{-1}$ & 2178.38 & 1664.16 & 1654.71 & 1925.20 & 2286.92 & 0.11 \\
\hline $6 \mathrm{~m} \mathrm{~s}^{-1}$ & 2393.26 & 1473.15 & 1278.34 & 2002.01 & 2562.63 & 0.40 \\
\hline $8 \mathrm{~m} \mathrm{~s}^{-1}$ & 2777.83 & 1211.56 & 528.77 & 2149.27 & 3041.96 & 1.11 \\
\hline $10 \mathrm{~m} \mathrm{~s}^{-1}$ & 2838.75 & 1171.94 & 499.51 & 2043.34 & 3155.85 & 1.93 \\
\hline \multicolumn{7}{|c|}{ Ambient Temperature, $24{ }^{\circ} \mathrm{C}$} \\
\hline \multirow{2}{*}{ Crosswind Speed } & \multicolumn{5}{|c|}{ Optimal Circulating Cooling Water Mass Flow Rate (kg/s) } & \multirow{2}{*}{$\begin{array}{l}\text { Reduced Standard Coal } \\
\text { Consumption Rate (g/kWh) }\end{array}$} \\
\hline & Sector 1 & Sector 2 & Sector 3 & Sector 4 & Sector 5 & \\
\hline $2 \mathrm{~m} \mathrm{~s}^{-1}$ & 1999.84 & 1854.88 & 1938.50 & 1889.98 & 2026.19 & 0.10 \\
\hline $4 \mathrm{~m} \mathrm{~s}^{-1}$ & 2173.35 & 1666.33 & 1660.15 & 1923.86 & 2285.69 & 0.11 \\
\hline $6 \mathrm{~m} \mathrm{~s}^{-1}$ & 2414.87 & 1445.75 & 1250.30 & 2003.51 & 2594.95 & 0.41 \\
\hline $8 \mathrm{~m} \mathrm{~s}^{-1}$ & 2762.57 & 1196.93 & 544.44 & 2146.66 & 3058.79 & 1.17 \\
\hline $10 \mathrm{~m} \mathrm{~s}^{-}$ & 2881.11 & 1153.79 & 478.08 & 2017.62 & 3178.79 & 2.11 \\
\hline \multicolumn{7}{|c|}{ Ambient Temperature, $32{ }^{\circ} \mathrm{C}$} \\
\hline \multirow{2}{*}{ Crosswind Speed } & \multicolumn{5}{|c|}{ Optimal Circulating Cooling Water Mass Flow Rate (kg/s) } & Reduced Standard Coal \\
\hline & Sector 1 & Sector 2 & Sector 3 & Sector 4 & Sector 5 & Consumption Rate (g/kWh) \\
\hline $2 \mathrm{~m} \mathrm{~s}^{-1}$ & 1988.19 & 1872.34 & 1978.05 & 1878.12 & 1992.69 & 0.10 \\
\hline $4 \mathrm{~m} \mathrm{~s}^{-1}$ & 2177.27 & 1664.76 & 1658.10 & 1923.56 & 2285.70 & 0.11 \\
\hline $6 \mathrm{~m} \mathrm{~s}^{-1}$ & 2391.55 & 1468.60 & 1283.56 & 1996.82 & 2568.85 & 0.45 \\
\hline $8 \mathrm{~m} \mathrm{~s}^{-1}$ & 2765.03 & 1185.27 & 574.76 & 2145.98 & 3038.35 & 1.34 \\
\hline $10 \mathrm{~m} \mathrm{~s}^{-1}$ & 2901.03 & 1132.90 & 457.30 & 2028.48 & 3189.67 & 2.50 \\
\hline
\end{tabular}

This means that the operation economy of a thermal power plant with indirect dry cooling system can be effectively enhanced by optimizing the circulating cooling water distribution. Moreover, the optimization of circulating cooling water is actually independent of crosswind direction, hence, it has strong significance in engineering practice.

\section{Conclusions}

Using a practical $660 \mathrm{MW}$ thermal power plant with an indirect dry cooling system as research object, a calculating model for its thermal-fluid process was built. Further, by means of evolution strategies algorithm, an iterative calculating process was established. With this calculating process, the optimal circulating cooling water distributions which lead to the minimum standard coal consumption rates under different ambient temperatures and crosswind speeds were calculated. The following conclusions can be obtained.

(1) Under crosswind conditions, the optimal water distribution is as follows: the windward sector has the most circulating cooling water, and the leeward sector takes second place, while the lateral sector is allocated the least circulating cooling water.

(2) For the optimal circulating cooling water distribution, the difference of water mass flow rates among sectors becomes bigger with the increase in crosswind speed. However, ambient temperature almost has no impact on the circulating cooling water distribution.

(3) The optimization of circulating cooling water distribution hardly affects the air side thermal-fluid performance of the natural draft dry cooling tower, but on the other hand, for the water side, the homogeneity of outlet water temperatures among sectors is improved.

(4) When circulating cooling water is distributed optimally, the standard coal consumption rate can be always reduced under all the investigated crosswind speeds. From a 
general view, with the increase in ambient temperature and crosswind speed, more standard coal is saved for each kilowatt-hour. Under ambient temperature of 32 ${ }^{\circ} \mathrm{C}$ and crosswind speed of $10 \mathrm{~m} \mathrm{~s}^{-1}$, the standard coal consumption rate could be reduced as much as $2.50 \mathrm{~g} / \mathrm{kWh}$.

Author Contributions: Conceptualization, H.W. and T.W.; methodology, Z.L.; software, Z.L.; validation, X.D.; formal analysis, Z.L.; investigation, T.W.; resources, X.D.; data curation, Z.L.; writingoriginal draft preparation, T.W.; writing-review and editing, H.W.; visualization, Z.L.; supervision, H.W.; project administration, X.D.; funding acquisition, X.D. All authors have read and agreed to the published version of the manuscript.

Funding: This research was funded by the national "973 Program" of China grant number No. 2015CB251503 and the Fundamental Research Funds for the Central Universities grant number 2020YJ002.

Institutional Review Board Statement: Not applicable.

Informed Consent Statement: Not applicable.

Data Availability Statement: Not applicable.

Acknowledgments: The financial supports for this research project from the national "973 Program" of China (No. 2015CB251503) and the Fundamental Research Funds for the Central Universities (2020YJ002) are gratefully acknowledged.

Conflicts of Interest: The authors declare no conflict of interest.

\section{Abbreviations}

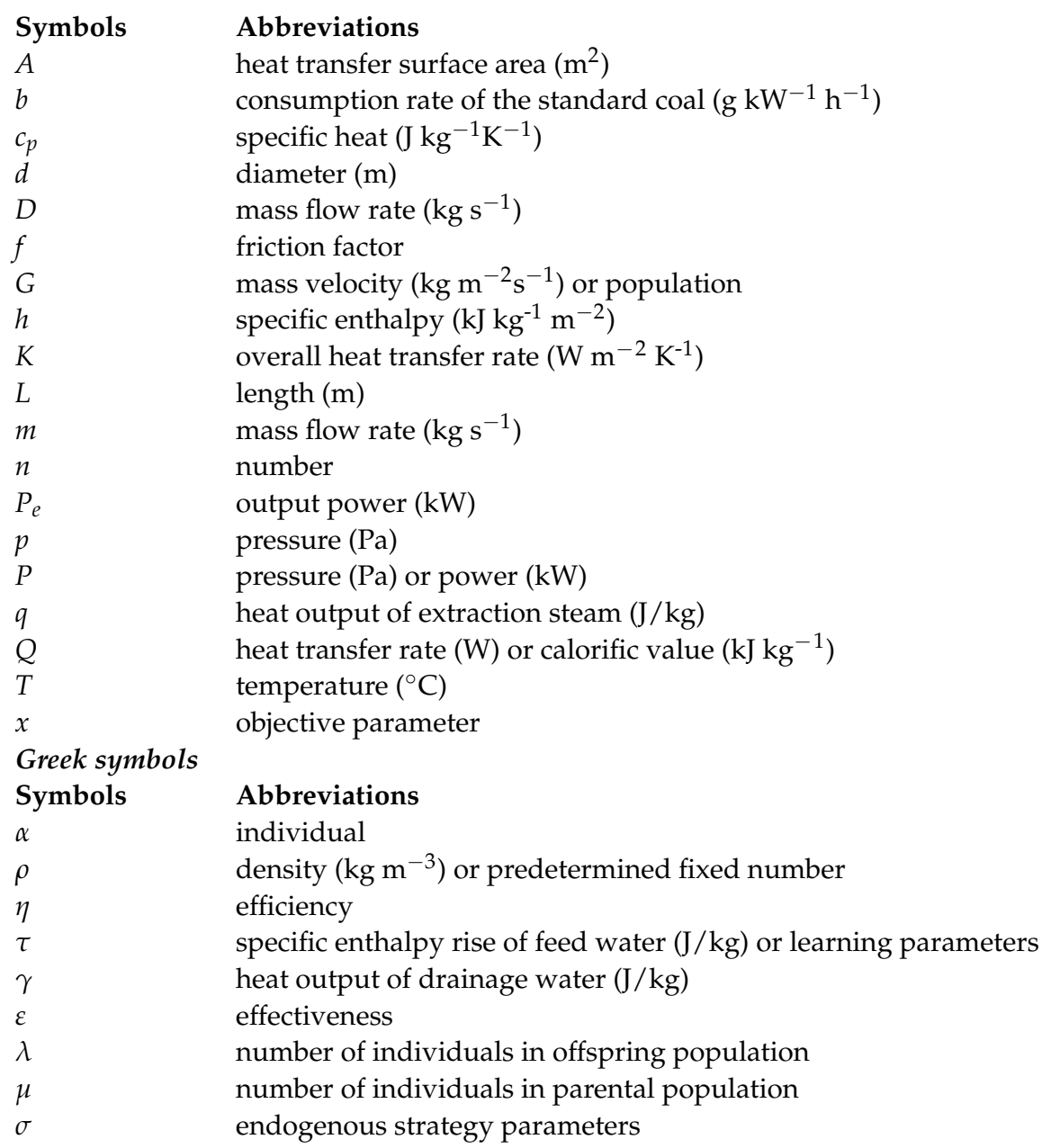




$\begin{array}{ll}\text { Subscripts } & \\ \text { Symbols } & \text { Abbreviations } \\ 0 & \text { initialized } \\ 1 & \text { inlet } \\ \text { a } & \text { air } \\ \text { b } & \text { bundle or boiler } \\ \text { cl } & \text { cooling column } \\ \text { es } & \text { extraction steam } \\ \text { g } & \text { generator } \\ \text { m } & \text { mechanical } \\ \text { ms } & \text { main steam } \\ \text { off } & \text { offspring } \\ \text { p } & \text { pump } \\ \text { par } & \text { parental } \\ \text { reh } & \text { reheat steam } \\ \text { sc } & \text { standard coal } \\ \text { tb } & \text { tubes per bundle } \\ \text { w } & \text { water } \\ \text { wp } & \text { water pass }\end{array}$

\section{References}

1. Kröger, D.G. Air-Cooled Heat Exchangers and Cooling Towers: Thermal-Flow Performance Evaluation and Design; PennWell Books: St Tulsa, OK, USA, 2004; Volume 1.

2. $\mathrm{Wu}, \mathrm{T}$.; Ge, Z.; Yang, L.; Du, X. Flow deflectors to release the negative defect of natural wind on large scale dry cooling tower. Int J. Heat Mass. Tran. 2019, 128, 248-269. [CrossRef]

3. Preez, A.F.; Kröger, D.G. Effect of wind on performance of a dry-cooling tower. Heat Recovery Syst. CHP 1993, 13, 139-146. [CrossRef]

4. Preez, A.F. The Influence of Cross-Winds on the Performance of Natural Draft Dry-Cooling Towers. Ph.D. Thesis, University of Stellenbosch, Stellenboschk, South Africa, 1992.

5. Preez, A.F.; Kröger, D.G. The effect of the heat exchanger arrangement and wind-break walls on the performance of natural draft dry-cooling towers subjected to cross-winds. J. Wind Eng. Ind. Aerodyn. 1995, 58, 293-303. [CrossRef]

6. Al-Waked, R.; Behina, M. The performance of natural draft dry cooling towers under crosswind: CFD study. Int. J. Energy Res. 2004, 28, 147-161. [CrossRef]

7. Su, M.D.; Tang, G.F.; Fu, S. Numerical simulation of fluid flow and thermal performance of a dry-cooling tower under cross wind condition. J. Wind Eng. Ind. Aerodyn. 1999, 79, 289-306. [CrossRef]

8. Yang, L.J.; Chen, L.; Du, X.Z.; Yang, Y.P. Effects of ambient winds on the thermo-flow performances of indirect dry cooling system in a power plant. Int. J. Therm. Sci. 2013, 64, 178-187. [CrossRef]

9. Yang, L.J.; Wu, X.P.; Du, X.Z.; Yang, Y.P. Dimensional characteristics of wind effects on the performance of indirect dry cooling system with vertically arranged heat exchanger bundles. Int. J. Heat Mass. Tran. 2013, 67, 853-866. [CrossRef]

10. Zhao, Y.B.; Long, G.; Sun, F.; Li, Y.; Zhang, C. Numerical study on the cooling performance of dry cooling tower with vertical two-pass column radiators under crosswind. Appl. Therm. Eng. 2015, 75, 1106-1117. [CrossRef]

11. Zhao, Y.; Sun, F.; Li, Y.; Long, G.; Yang, Z. Numerical study on the cooling performance of natural draft dry cooing tower with vertical delta radiators under constant heat load. Appl. Energy 2015, 149, 225-237. [CrossRef]

12. Al-Waked, R.; Behina, M. The effect of windbreak walls on the thermal performance of natural draft dry cooling towers. Heat Transf. Eng. 2005, 26, 50-62. [CrossRef]

13. Zhai, Z.; Fu, S. Improving cooling efficiency of dry-cooling towers under cross-wind conditions by using wind-break methods. Appl. Therm. Eng. 2006, 26, 1008-1017. [CrossRef]

14. Chen, L.; Yang, L.; Du, X.; Yang, Y. Performance improvement of natural draft dry cooling system by interior and exterior windbreaker configurations. Int. J. Heat Mass. Tran. 2016, 96, 42-63. [CrossRef]

15. Zavaragh, H.G.; Ceviz, M.A.; Tabar, M.T.S. Analysis of windbreaker combinations on steam power plant natural draft dry cooling towers. Appl. Therm. Eng. 2016, 99, 550-559. [CrossRef]

16. Lu, Y.; Guan, Z.; Gurgenci, H.; Zou, Z. Windbreak walls revers the negative effect of crosswind in short natural draft dry cooling towers into a performance enhancement. Int. J. Heat Mass. Tran. 2013, 63, 162-170. [CrossRef]

17. Lu, Y.; Guan, Z.; Gurgenci, H.; Alkhedhair, A.; He, S. Experimental investigation into the positive effects of a tri-blade-like windbread wall on small size natural draft dry cooling towers. Appl. Therm. Eng. 2016, 105, 1000-1012. [CrossRef]

18. Lu, Y.; Gurgenci, H.; Guan, Z.; He, S. The influence of windbreak wall orientation on the cooling performance of small natural draft dry cooling towers. Int. J. Heat Mass. Tran. 2014, 79, 1059-1069. [CrossRef]

19. Wang, W.; Zhang, H.; Li, Z.; Lv, J.; Ni, W.; Li, Y. Adoption of enclosure and windbreaks to prevent the degradation of the cooling performance for a natural draft dry cooling tower under crosswind conditions. Energy 2016, 116, 1360-1369. [CrossRef] 
20. Wang, W.; Zhang, H.; Liu, P.; Li, Z.; Lv, J.; Ni, W. The cooling performance of a natural draft dry cooling tower under crosswind and an enclosure approach to cooling efficiency enhancement. Appl. Energy 2017, 186, 336-346. [CrossRef]

21. Gu, H.; Wang, H.; Gu, Y.; Yao, J. A numerical study on the mechanism and optimization of wind-break structures for indirect air-cooling towers. Energy Convers. Manag. 2016, 108, 43-49. [CrossRef]

22. Zhao, Y.; Long, G.; Sun, F.; Li, Y.; Zhang, C.; Liu, J. Effect mechanism of air deflectors on the cooling performance of dry cooling tower with vertical delta radiators under crosswind. Energy Convers. Manag. 2015, 93, 321-331. [CrossRef]

23. Ma, H.; Si, F.; Kong, Y.; Zhu, K.; Yan, W. Wind-break walls with optimized settings angles for natural draft dry cooling tower with vertical radiators. Appl. Therm. Eng. 2017, 112, 326-339. [CrossRef]

24. Goodarzi, M. A proposed stack configuration for dry cooling tower to improve cooling efficiency under crosswind. J. Wind Eng. Ind. Aerodyn. 2010, 98, 858-863. [CrossRef]

25. Goodarzi, M.; Ramezanpour, R. Alternative geometry for cylindrical natural draft cooling tower with higher cooling efficiency under crosswind condition. Energy Convers. Manag. 2014, 77, 243-249. [CrossRef]

26. Liao, H.T.; Yang, L.J.; Du, X.Z.; Yang, Y.P. Triangularly arranged heat exchanger bundles to restrain wind effects on natural draft dry cooling system. Appl. Therm. Eng. 2016, 99, 313-324. [CrossRef]

27. Kong, Y.; Wang, W.; Yang, L.; Du, X.; Yang, Y. A novel natural draft dry cooling system with bilaterally arranged air-cooled heat exchanger. Int. J. Therm. Sci. 2017, 112, 318-334. [CrossRef]

28. Li, X.; Xia, L.; Gurgenci, H.; Guan, Z. Performance enhancement for the natural draft dry cooling tower under crosswind condition by optimizing the water distribution. Int. J. Heat Mass. Tran. 2017, 107, 271-280. [CrossRef]

29. Wei, H.; Wu, T.; Ge, Z.; Yang, L.; Du, X. Entransy analysis optimization of cooling water flow distribution in a dry cooling tower of power plant under summer crosswinds. Energy 2019, 166, 1229-1240. [CrossRef]

30. Wang, X.; Yang, L.; Du, X.; Yang, Y. Performance improvement of natural draft dry cooling system by water flow distribution under crosswinds. Int. J. Heat Mass. Tran. 2017, 108, 1924-1940. [CrossRef]

31. Goodarzi, M.; Amooie, H. Heat transfer enhancement in a natural draft dry cooling tower under crosswind operation with heterogeneous water distribution. Atw. Int. J. Nucl. Power 2016, 61, 252-259.

32. Chu, F.; Xiao, G.; Yang, G. Mass transfer characteristics and energy penalty analysis of MEA regeneration process in packed column. Sustain. Energy Fuels 2020. [CrossRef]

33. Ye, C.; Zheng, Y.; Xu, Y.; Li, G.; Dong, C.; Tang, Y.; Wang, Q. Energy and exergy analysis of poly-generation system of hydrogen and electricity via coal partial gasification. Comput. Chem. Eng. 2020, 141, 106911. [CrossRef]

34. Wu, T.; Ge, Z.; Yang, L.; Du, X. Modeling the performance of the indirect dry cooling system in a thermal power generating unit under variable ambient conditions. Energy 2019, 169, 625-636. [CrossRef]

35. Wu, T.; Wei, H.; Ge, Z.; Yang, L.; Du, X. Cooling water mass flow optimization for indirect dry cooling system of thermal power unit under variable output load. Int. J. Heat Mass. Tran. 2019, 133, 1-10. [CrossRef]

36. Buys, J.D.; Kröger, D.G. Cost-optimal design of dry cooling towers through mathematical programming techniques. Heat Transf. 1989, 111, 322-327. [CrossRef]

37. Back, T. Evolutionary Algorithms in Theory and Practice; Oxford University: Oxford, NY, USA, 1996.

38. Abad, A.; Elipe, A. Evolution strategies for computing periodic orbits. Math Comput. Simul. 2018, 146, 251-261. [CrossRef]

39. Alrashdi, Z.; Sayyafzadeh, M. $(\mu+\lambda)$ evolution strategy algorithm in well placement, trajectory, control and joint optimization. J. Petrol. Sci. Eng. 2019, 177, 1042-1058. [CrossRef]

40. Beyer, H.G.; Schwefel, H.P. Evolution strategies. Nat. Comput. 2002, 1, 3-52. [CrossRef]

41. Schwefel, H.P. Evolution and Optimum Seeking; John Wiley \& Sons Inc.: Hoboken, NJ, USA, 1995.

42. Kong, Y.Q.; Yang, L.J.; Du, X.Z.; Yang, Y.P. Effects of continuous and alternant rectangular slots on thermal-flow performance of plain finned tube bundles in in-link and staggered configurations. Int. J. Heat Mass. Tran. 2016, 93, 97-107. [CrossRef] 